\title{
Lumbar Scoliosis in Patients With Breast Cancer: Prevalence and Relationship With Breast Cancer Treatment, Age, Bone Mineral Density, and Body Mass Index
}

\author{
Sangeun Jung, MD, Mee Gang Kim, MD, Jong In Lee, MD, PhD \\ Department of Rehabilitation Medicine, Seoul St. Mary's Hospital, College of Medicine, \\ The Catholic University of Korea, Seoul, Korea
}

\begin{abstract}
Objective To identify the prevalence of lumbar scoliosis in breast cancer patients and to investigate the potential risk factors of lumbar scoliosis.

Methods A retrospective chart review was performed in breast cancer patients aged more than 40 years who underwent dual energy X-ray absorptiometry (DEXA) scanning between January 2014 and December 2014. We divided the patients into control and experimental groups in order to investigate the influence of breast cancer treatment. The curvature of the lumbar spine was measured by using the Cobb method on a DEXA scan. Scoliosis was defined by the presence of a curvature $10^{\circ}$ or larger. The variables, including age, bone mineral density (BMD), body mass index (BMI), and breast cancer treatments, were also obtained from the medical chart. Prevalence of lumbar scoliosis was evaluated, and it was compared between the two groups. The relationships between lumbar scoliosis and these variables were also investigated.

Results Lumbar scoliosis was present in 16 out of our 652 breast cancer patients. There was no difference in the prevalence of lumbar scoliosis between the control group $(7 / 316)$ and the experimental group $(9 / 336)(p=0.70)$. According to the logistic regression analysis, lumbar scoliosis had no significant association with operation, chemotherapy, hormone therapy, BMI, and BMD ( $>0.05)$. However, age showed a significant relationship with prevalence of lumbar scoliosis ( $\mathrm{p}<0.001$; odds ratio, 1.11; 95\% confidence interval, 1.054-1.170).

Conclusion Prevalence of lumbar scoliosis in patients with breast cancer was $2.45 \%$. Lumbar scoliosis had no association with breast cancer treatments, BMD, and BMI. Age was the only factor related to the prevalence of lumbar scoliosis.
\end{abstract}

Keywords Lumbar scoliosis, Prevalence, Breast cancer, DEXA

Received January 2, 2017; Accepted March 23, 2017

Corresponding author: Jong In Lee

Department of Rehabilitation Medicine, Seoul St. Mary's Hospital, College of Medicine, The Catholic University of Korea, 222 Banpo-daero, Seochogu, Seoul 06591, Korea. Tel: +82-2-2258-2822, Fax: +82-2-2258-2825, E-mail: ljikyh@catholic.ac.kr

ORCID: Sangeun Jung (https://orcid.org/0000-0001-7964-1510); Mee Gang Kim (https://orcid.org/0000-0001-7709-2079); Jong In Lee (https://orcid. org/0000-0002-8844-4807).

(c) This is an open-access article distributed under the terms of the Creative Commons Attribution Non-Commercial License (http://creativecommons.org/ licenses/by-nc/4.0) which permits unrestricted noncommercial use, distribution, and reproduction in any medium, provided the original work is properly cited. Copyright ( 2017 by Korean Academy of Rehabilitation Medicine 


\section{INTRODUCTION}

Lumbar scoliosis is one of the most prevalent problems caused by degenerative changes in the elderly. Prevalence of adult lumbar scoliosis has been reported to show a wide variability, ranging from $7.5 \%$ to $13.3 \%$ [1-5]. Although lumbar scoliosis can be asymptomatic, occasionally, it can cause low back pain, radiating pain in lower limbs, and neurogenic claudication. There is only limited knowledge about the risk factors associated with lumbar scoliosis, especially in the elderly.

Breast cancer is the most prevalent type of neoplasm in the female population. Patients diagnosed with breast cancer undergo surgery, chemotherapy, and hormone therapy. According to the guidance for management of breast cancer treatment-induced bone loss (2008), dual energy X-ray absorptiometry (DEXA) scanning is a routine screening technique suggested for all women over 50 years of age, and it is recommended for breast cancer patients in the postmenopausal period who are receiving aromatase inhibitors or who achieve premature menopause due to chemotherapy or ovarian suppression [6]. They have more chances of developing lumbar scoliosis, because hormone therapy can negatively affect bone quality and osteoporosis can be associated with scoliosis. In addition, almost every patient undergoes operative treatment including mass excision or mastectomy, and as a consequence, asymmetrical body mass distribution could cause imbalance in vertebral disc loading. To the best of our knowledge, there is no report about lumbar scoliosis in patients with breast cancer. Therefore, the primary purpose of this study was to identify the prevalence of lumbar scoliosis in breast cancer patients. The secondary purpose was to investigate the influence of breast cancer treatments, such as operation, chemotherapy, and hormone therapy, on lumbar scoliosis and to assess the relationship of lumbar scoliosis with age, bone mineral density (BMD), and body mass index (BMI).

\section{MATERIALS AND METHODS}

We included patients with breast cancer, aged more than 40 years, who underwent DEXA scanning at Seoul St. Mary's hospital, The Catholic University of Korea between January 2014 and December 2014. We divided the patients into two groups in order to investigate the influ- ence of breast cancer treatment. In the control group, we included individuals who were diagnosed with breast cancer, but did not receive breast cancer treatments before DEXA. In the experimental group, patients who started breast cancer treatments at least 2 years ago (initial treatments date between January 2009 and December 2011) were selected, because breast cancer therapy might not have an influence on lumbar scoliosis in a short period. Types of breast cancer treatments, including operation, chemotherapy, hormone therapy, and radiation therapy, were reviewed from the medical chart. The exclusion criteria were as follows: spine or hip joint operation in the past, previous chemotherapy, hormone or radiation treatment due to history of other cancer, bone metastasis, recurrent breast cancer, and bilateral breast cancer operation. This study was conducted with the approval of the committee of our institution.

The curvature of the lumbar spine was measured by using the Cobb method on a DEXA scan image in the anteroposterior view of the lumbar spine. The greatest curvatures of the lumbar spine were measured in cases with apparent curvatures, while the Cobb angle between the L1-L5 spine was used in cases with no obvious curvatures (Fig. 1). Pappou et al. [2] previously proved the validity of Cobb angle measurements on DEXA images as a diagnostic tool for lumbar scoliosis. Scoliosis was defined by

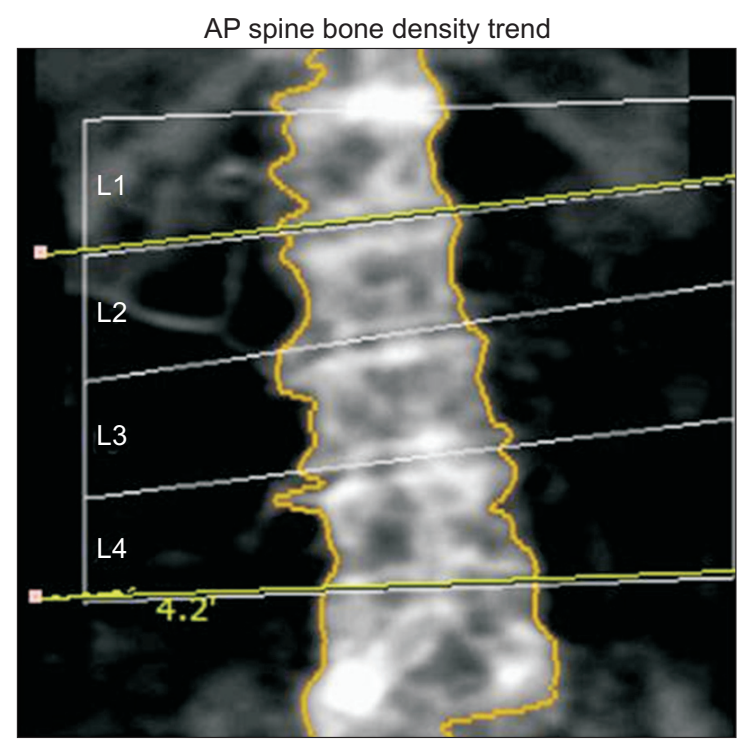

Fig. 1. Angle of lumbar scoliosis was measured by the Cobb method using dual energy X-ray absorptiometry (DEXA) scanning. 
the presence of a curvature $10^{\circ}$ or larger. In the current study, 40 patients were randomly selected to determine the intra- and inter-observer variability of the measurement. Reliability was high for all comparisons: intra-observer reliability was 0.902 and inter-observer reliability was 0.917 .

The variables, including age, $\mathrm{T}$ score of the spine and femoral neck, weight and height, were obtained from a DEXA scan. BMI $\left(\mathrm{kg} / \mathrm{m}^{2}\right)$ was calculated as the weight in kilograms divided by the square of the height in meters.

\section{Statistical analyses}

A Student t-test was performed to compare the demographics including age, BMI, BMD, and the Cobb angle between the experimental and control groups. ANCOVA adjusted for age was also performed. The prevalence of lumbar scoliosis was calculated as the ratio of the number of lumbar scoliosis patients to the total number of patients, and the difference in prevalence of lumbar scoliosis was analyzed using chi-square test. The logistic regression analysis was performed to determine the impact of independent variables, including operation, chemotherapy, radiation therapy, hormone therapy, age, $\mathrm{BMI}$, and $\mathrm{T}$ score of the femoral neck and spine, on the presence of lumbar scoliosis. In several previous studies that investigated the prevalence of adult lumbar scoliosis, the 10-year value for age-span was used to stratify the subjects into different age categories $[5,7,8]$. The prevalence of lumbar scoliosis in each group was calculated, respectively, and the difference in prevalence of lumbar scoliosis was analyzed using chi-square test. In addition, subgroups for each treatment in the experimental group were analyzed to evaluate the curvature of lumbar scoliosis using Student t-test and ANOVA while chi-square test was used to determine the prevalence of lumbar scoliosis. $\mathrm{p}<0.05$ was considered statistically significant.

SPSS system software ver. 24 (IBM, Armonk, NY, USA) was used for all statistical analyses investigating the prevalence of lumbar scoliosis and its relationship with variables such as age, BMI, BMD, operation, chemotherapy, and hormone therapy.

\section{RESULTS}

\section{Demographics}

In our current study, total 652 women met the criteria;
316 women were included in the control group, and 336 women were included in the experimental group. The demographic characteristics that differed between the two groups were age and BMD (Table 1). Women in the control group were younger than those in the experimental group $(\mathrm{p}<0.001)$. $\mathrm{T}$ scores of the spine and femoral neck were higher in the control group than in the experimental group ( $\mathrm{p}<0.001$ and $\mathrm{p}=0.016$, respectively). After performing ANCOVA adjusted for age, $T$ score of the spine in the experimental group was still significantly lower than that in the control group $(p<0.001)$, whereas $\mathrm{T}$ score of the femoral neck showed no significant difference between the two groups ( $\mathrm{p}=0.74)$.

Lumbar scoliosis was present in 16 out of our 652 adult patients, at a prevalence rate of $2.45 \%$ (Table 1 ). There

Table 1. Demographics of the patients $(n=652)$

\begin{tabular}{|c|c|c|c|}
\hline & $\begin{array}{c}\text { Control } \\
\text { group } \\
(\mathrm{n}=\mathbf{3 1 6})\end{array}$ & $\begin{array}{c}\text { Experimental } \\
\text { group } \\
(\mathrm{n}=336)\end{array}$ & p-value \\
\hline Age (yr) & $54.13 \pm 8.90$ & $56.82 \pm 9.00$ & $<0.001$ \\
\hline BMI $\left(\mathrm{kg} / \mathrm{m}^{2}\right)$ & $24.161 \pm 9.491$ & $23.352 \pm 3.234$ & 0.14 \\
\hline $\mathrm{BMD}^{\mathrm{a})}$ & $-0.823 \pm 1.468$ & $-1.399 \pm 1.155$ & $<0.001$ \\
\hline Hip $B M D^{b)}$ & $-2.001 \pm 1.007$ & $-2.179 \pm 0.878$ & 0.016 \\
\hline Cobb angle & $2.41 \pm 2.85$ & $2.19 \pm 3.26$ & 0.35 \\
\hline Lumbar scoliosis ${ }^{c)}$ & $7(2.22)$ & $9(2.68)$ & 0.70 \\
\hline \multicolumn{4}{|l|}{ Operation } \\
\hline BCS & - & 221 & \\
\hline MRM & - & 115 & \\
\hline \multicolumn{4}{|l|}{ Hormone therapy } \\
\hline None & - & 136 & \\
\hline Tamoxifen & - & 126 & \\
\hline $\mathrm{AI}$ & - & 94 & \\
\hline Mixed & - & 10 & \\
\hline Chemotherapy & - & 195 & \\
\hline Radiation therapy & - & 235 & \\
\hline
\end{tabular}

Values are presented as mean \pm standard deviation or number.

BMI, body mass index; BMD, bone mineral density; BCS, breast-conserving surgery (lumpectomy); MRM, modified radical mastectomy; AI, aromatase inhibitor.

a) $\mathrm{T}$ score of the spine.

${ }^{\mathrm{b})} \mathrm{T}$ score of the femoral neck.

${ }^{c}$ Number of lumbar scoliosis patients (ratio of the number of lumbar scoliosis patients to the total number of patients). 
was no difference in the prevalence of lumbar scoliosis between the control group (7/316) and the experimental group $(9 / 336)(p=0.70)$. The curvature of lumbar scoliosis showed no statistical difference between the two groups $(\mathrm{p}=0.35)$.

\section{Relationship between lumbar scoliosis and other} factors

According to the logistic regression analysis, lumbar scoliosis had no significant association with operation $(p=0.36)$ and both breast cancer treatments, i.e., chemotherapy $(\mathrm{p}=0.70)$ and hormone therapy $(\mathrm{p}=0.52)$. Subanalysis of different types of operation showed that lumbar scoliosis had no significant association with breastconserving surgery $(p=0.47)$ or mastectomy $(p=0.77)$. $\mathrm{BMI}$ and $\mathrm{T}$ scores of the femoral neck and spine were not statistically relevant to the prevalence of lumbar scoliosis. Age was the only variable related to the prevalence of lumbar scoliosis ( $\mathrm{p}<0.001$; odds ratio, 1.11 for 1 -year age

Table 2. Logistic regression analysis of variables associated with lumbar scoliosis

\begin{tabular}{llc}
\hline & OR (95\% CI) & p-value \\
\hline Operation & $2.88(0.29-28.11)$ & 0.36 \\
Hormone therapy & $0.58(0.11-3.08)$ & 0.52 \\
Chemotherapy & $1.31(0.32-5.93)$ & 0.70 \\
Radiation therapy & $0.40(0.07-2.17)$ & 0.28 \\
BMD $^{\text {a) }}$ & $1.89(0.60-5.93)$ & 0.27 \\
BMI & $0.99(0.89-1.11)$ & 0.96 \\
Age & $1.11(1.06-1.20)$ & $<0.001^{*}$ \\
\hline
\end{tabular}

OR, odds ratio; CI, confidence interval; BMD, bone mineral density; BMI, body mass index.

${ }^{\text {a) }}$ Defined as osteoporosis ( $\mathrm{T}$ score of the spine and femoral neck lower than -2.5).

${ }^{*} \mathrm{p}<0.05$.

Table 3. Prevalence of lumbar scoliosis according to the age group

\begin{tabular}{|ccccc}
\hline $\begin{array}{c}\text { Age } \\
\text { group } \\
\text { (yr) }\end{array}$ & $\begin{array}{c}\text { No. of lumbar } \\
\text { scoliosis } \\
\text { patients }\end{array}$ & $\begin{array}{c}\text { No. of } \\
\text { total } \\
\text { subjects }\end{array}$ & $\begin{array}{c}\text { Prevalence } \\
\text { of scoliosis } \\
\text { (\%) }\end{array}$ & -value \\
\hline $40-49$ & 0 & 180 & 0 & \\
\hline $50-59$ & 5 & 272 & 1.8 & \\
$60-69$ & 6 & 148 & 4.1 & \\
$\geq 70$ & 5 & 52 & 9.4 & $<0.001$ \\
Total & 16 & 632 & 2.24 & \\
\hline
\end{tabular}

difference; 95\% confidence interval, 1.054-1.170) (Table 2). Table 3 shows that the prevalence of lumbar scoliosis increased almost linearly in the subgroups of the 10-year age $\operatorname{span}(\mathrm{p}<0.001)$.

Curvature and prevalence of lumbar scoliosis in the experimental group

There was no difference in the prevalence of lumbar scoliosis between subgroups of all treatments including operation, hormone therapy, chemotherapy, and radiation therapy. The Cobb angle indicating lumbar scoliosis between subgroups of hormone therapy showed a statistical difference $(\mathrm{p}<0.05)$. The subgroup with tamoxifen treatment showed a lower Cobb angle than the other subgroups. However, after performing ANCOVA adjusted for age, the curvature of lumbar scoliosis between these subgroups showed no statistical difference (Table 4).

Table 4. Curvature and prevalence of lumbar scoliosis in the experimental group

\begin{tabular}{|c|c|c|}
\hline & Cobb angle $\left({ }^{\circ}\right)$ & Lumbar scoliosis $^{\text {b) }}$ \\
\hline \multicolumn{3}{|l|}{ Operation } \\
\hline $\operatorname{BCS}(n=211)$ & $2.02 \pm 3.20$ & $6(2.22)$ \\
\hline $\operatorname{MRM}(\mathrm{n}=115)$ & $2.51 \pm 3.35$ & $3(2.68)$ \\
\hline $\mathrm{p}$-value & 0.19 & 0.95 \\
\hline \multicolumn{3}{|l|}{ Hormone therapy } \\
\hline None $(\mathrm{n}=136)$ & $2.28 \pm 2.70$ & $2(2.22)$ \\
\hline Tamoxifen $(n=126)$ & $1.66 \pm 2.86$ & $2(2.68)$ \\
\hline $\mathrm{AI}(\mathrm{n}=94)$ & $2.80 \pm 2.70$ & $5(2.22)$ \\
\hline p-value & $<0.05^{*}(0.73)^{\mathrm{a})}$ & 0.17 \\
\hline \multicolumn{3}{|l|}{ Chemotherapy } \\
\hline None $(\mathrm{n}=141)$ & $2.32 \pm 3.07$ & $5(2.22)$ \\
\hline Yes $(n=195)$ & $2.10 \pm 3.39$ & $4(2.68)$ \\
\hline p-value & 0.62 & 0.95 \\
\hline \multicolumn{3}{|l|}{ Radiation therapy } \\
\hline None $(n=101)$ & $2.45 \pm 3.08$ & $2(2.22)$ \\
\hline Yes $(n=235)$ & $2.08 \pm 3.33$ & $7(2.68)$ \\
\hline p-value & 0.31 & 0.95 \\
\hline
\end{tabular}

Values are presented as mean \pm standard deviation.

BCS, breast-conserving surgery (lumpectomy); MRM, modified radical mastectomy; AI, aromatase inhibitor.

${ }^{a)} \mathrm{p}$-value after adjustment for age.

${ }^{b)}$ Number of lumbar scoliosis patients (ratio of the number of lumbar scoliosis patients to the total number of patients).

${ }^{*} \mathrm{p}<0.05$. 


\section{DISCUSSION}

Lumbar scoliosis in the adult population has been receiving attention with the worldwide population getting older. Adult lumbar scoliosis can be explained by complex pathologic entities, which have not been sufficiently understood. One possible explanation for lumbar scoliosis is that it could originate from a cascade of degenerative changes including asymmetrical collapse of the intervertebral disc and facet joint hypertrophy $[9,10]$.

Few studies have investigated the prevalence of lumbar scoliosis, and this prevalence ranges from $7.5 \%$ to $13.3 \%$ [1-5]. Also some studies with different age subgroups showed a remarkable increase in the prevalence of lumbar scoliosis with an increase in age $[1,4,5,8]$. Our study showed a clear correlation between increasing age and higher prevalence of lumbar scoliosis. However, the prevalence rate of lumbar scoliosis of $2.45 \%$ in our study was lower than the prevalence rate of $13.3 \%$ in a previous study among 2,395 Chinese patients aged more than 40 years. We also evaluated variables including BMD and BMI. Since both lumbar scoliosis and osteoporosis have been associated with an increase in age, the elderly might have a higher chance of developing both diseases. The relationship between lumbar scoliosis and osteoporosis is unclear. A research claimed that their relationship is a predisposing factor to each other [11,12], while other studies showed no association $[4,13]$. In the case of BMI, Xu et al. [5] found no association between BMI and scoliosis, whereas Urrutia et al. [4] claimed that lower BMI was an independent predictor of adult scoliosis. When we adjusted for age and other variables, including cancer treatments, BMD or BMI were not relevant to the presence of lumbar scoliosis. This might imply that lower BMD itself does not act as a main determinant for lumbar scoliosis. Another possible explanation for this phenomenon is that spinal degeneration or collapse of the vertebrae could incorrectly increase lumbar BMD in DEXA scan measurement. Pappou et al. [2] showed that scoliotic patients demonstrated discordantly high spinal BMD values, and an increasing discrepancy with age was noted.

Breast cancer survivors usually undergo treatments such as chemotherapy, hormone therapy, radiation therapy, and operation. Accordingly, we presumed that these treatments might increase the prevalence of lumbar sco- liosis because of the risk of bone loss and imbalance in vertebral disk loading. Hormone therapy has a negative effect on bone quality. Especially, the use of an aromatase inhibitor has been found to be related to an increased risk of bone loss and fractures [14-16]. On the other hand, the current use of tamoxifen has been reported to be related to preservation of BMD in premenopausal women. Previous treatment with tamoxifen correlates with lower values of bone turnover markers $[17,18]$. However, its protective effect on diseases such as osteoporotic fracture has been controversial [19-21]. In the current study, hormone therapy, regardless of the use of tamoxifen or aromatase inhibitor, was not associated with the prevalence of lumbar scoliosis. Although the patients using tamoxifen tend to have a lesser curvature of lumbar scoliosis, there was no statistical difference after adjusting for the age factor. This could be explained by different types of medications used depending on the age. Tamoxifen was usually used for premenopausal breast cancer patients, while aromatase inhibitor was used for older women. Asymmetrical body mass distribution or tightness of the post-operative scar could cause an imbalance in posture, which is the risk factor of lumbar scoliosis. Previous authors have theorized about the biomechanical role of asymmetrical loading in progression of the scoliotic deformity. Scoliotic-like deformities have also been produced in otherwise healthy animals by applying asymmetrical loads across the spine [22-26]. Nevertheless, operative treatment does not have an impact on the incidence of scoliosis. Our results might be explained by a small amount of asymmetric loading difference. The type of operation includes mass excision and mastectomy. In the case of a small sized tumor mass, simple excision should be adequate, and this small amount has no effect on body asymmetric loads. Our result also showed no statistical differences in the prevalence of lumbar scoliosis between breast conserving surgery and mastectomy groups. To determine whether the type of operation can cause spine deformity with different amounts, a larger number of breast cancer patients need to be investigated. There was one study which evaluated the Cobb angle in 60 breast cancer patients by using chest radiographs obtained before mastectomy and 12 months after mastectomy. The result of the study showed that the Cobb angle decreased in 14 out of 60 patients and it increased in 38 out of 60 patients after unilateral mastectomy. The 
angular change was found to be independent of the mastectomy side and only two patients developed scoliosis [27]. Direct comparison of the previous report with our study was not possible due to differences in the levels of the spine and the method. The previous study included the thoracic level or the thoracolumbar level, and the authors did not examine the overall prevalence of scoliosis. To the best of our knowledge, this is the first research on adult lumbar scoliosis associated with breast cancer.

There are some limitations to the current study. Firstly, it was indistinguishable whether lumbar scoliosis developed after treatment or before treatment because this was not a prospective study. Furthermore, we could not measure the difference in the Cobb angle according to breast cancer treatments in the experimental group because BMD assessment was not performed before the treatments. Secondly, as mentioned earlier, further work should include a larger number of breast cancer patients to evaluate different types of hormone therapy and operations, because the prevalence of lumbar scoliosis was lesser than we had initially expected. Thirdly, follow-up periods were short; therefore, prolonged investigation is necessary to confirm the long-term effect of breast cancer treatment on lumbar scoliosis. Lastly, we could not assess the possibility of whole spine deformity after breast cancer treatment because the thoracic spine level was not included in the current study.

In conclusion, prevalence of lumbar scoliosis in patients with breast cancer was $2.45 \%$. Lumbar scoliosis had no association with breast cancer treatments, including chemotherapy, hormone therapy, and operation. $\mathrm{BMI}$ and $\mathrm{T}$ scores of the femoral neck and spine were also not relevant to the prevalence of lumbar scoliosis. Age was the only factor related to the prevalence of lumbar scoliosis. However, this study is a cross-sectional study; therefore, cautious interpretation of the results and further study with a larger number of patients are required.

\section{CONFLICT OF INTEREST}

No potential conflict of interest relevant to this article was reported.

\section{REFERENCES}

1. Kebaish KM, Neubauer PR, Voros GD, Khoshnevisan
MA, Skolasky RL. Scoliosis in adults aged forty years and older: prevalence and relationship to age, race, and gender. Spine (Phila Pa 1976) 2011;36:731-6.

2. Pappou IP, Girardi FP, Sandhu HS, Parvataneni HK, Cammisa FP Jr, Schneider R, et al. Discordantly high spinal bone mineral density values in patients with adult lumbar scoliosis. Spine (Phila Pa 1976) 2006;31: 1614-20.

3. Perennou D, Marcelli C, Herisson C, Simon L. Adult lumbar scoliosis. Epidemiologic aspects in a low-back pain population. Spine (Phila Pa 1976) 1994;19:123-8.

4. Urrutia J, Diaz-Ledezma C, Espinosa J, Berven SH. Lumbar scoliosis in postmenopausal women: prevalence and relationship with bone density, age, and body mass index. Spine (Phila Pa 1976) 2011;36:73740.

5. Xu L, Sun X, Huang S, Zhu Z, Qiao J, Zhu F, et al. Degenerative lumbar scoliosis in Chinese Han population: prevalence and relationship to age, gender, bone mineral density, and body mass index. Eur Spine J 2013;22:1326-31.

6. Reid DM, Doughty J, Eastell R, Heys SD, Howell A, McCloskey EV, et al. Guidance for the management of breast cancer treatment-induced bone loss: a consensus position statement from a UK Expert Group. Cancer Treat Rev 2008;34 Suppl 1:S3-18.

7. Hong JY, Suh SW, Modi HN, Hur CY, Song HR, Park $\mathrm{JH}$. The prevalence and radiological findings in 1347 elderly patients with scoliosis. J Bone Joint Surg Br 2010;92:980-3.

8. Watanuki A, Yamada H, Tsutsui S, En-yo Y, Yoshida M, Yoshimura N. Radiographic features and risk of curve progression of de-novo degenerative lumbar scoliosis in the elderly: a 15-year follow-up study in a community-based cohort. J Orthop Sci 2012;17:526-31.

9. Aebi M. The adult scoliosis. Eur Spine J 2005;14:92548.

10. Birknes JK, White AP, Albert TJ, Shaffrey CI, Harrop JS. Adult degenerative scoliosis: a review. Neurosurgery 2008;63(3 Suppl):94-103.

11. Thevenon A, Pollez B, Cantegrit F, Tison-Muchery F, Marchandise X, Duquesnoy B. Relationship between kyphosis, scoliosis, and osteoporosis in the elderly population. Spine (Phila Pa 1976) 1987;12:744-5.

12. Velis KP, Healey JH, Schneider R. Osteoporosis in unstable adult scoliosis. Clin Orthop Relat Res 1988; 
(237):132-41.

13. Robin GC. Scoliosis in the elderly: idiopathic or osteoporotic? Clin Orthop Relat Res 1986;(205):311-2.

14. Baum M, Budzar AU, Cuzick J, Forbes J, Houghton JH, Klijn JG, et al. Anastrozole alone or in combination with tamoxifen versus tamoxifen alone for adjuvant treatment of postmenopausal women with early breast cancer: first results of the ATAC randomised trial. Lancet 2002;359:2131-9.

15. Coleman RE, Banks LM, Girgis SI, Kilburn LS, Vrdoljak E, Fox J, et al. Skeletal effects of exemestane on bonemineral density, bone biomarkers, and fracture incidence in postmenopausal women with early breast cancer participating in the Intergroup Exemestane Study (IES): a randomised controlled study. Lancet Oncol 2007;8:119-27.

16. Rabaglio M, Sun Z, Price KN, Castiglione-Gertsch M, Hawle H, Thurlimann B, et al. Bone fractures among postmenopausal patients with endocrine-responsive early breast cancer treated with 5 years of letrozole or tamoxifen in the BIG 1-98 trial. Ann Oncol 2009;20: 1489-98.

17. Hadji P, Ziller M, Kieback DG, Dornoff W, Tessen HW, Menschik T, et al. Effects of exemestane and tamoxifen on bone health within the Tamoxifen Exemestane Adjuvant Multicentre (TEAM) trial: results of a German, 12-month, prospective, randomised substudy. Ann Oncol 2009;20:1203-9.

18. Servitja S, Nogues X, Prieto-Alhambra D, MartinezGarcia M, Garrigos L, Pena MJ, et al. Bone health in a prospective cohort of postmenopausal women receiving aromatase inhibitors for early breast cancer.
Breast 2012;21:95-101.

19. Cooke AL, Metge C, Lix L, Prior HJ, Leslie WD. Tamoxifen use and osteoporotic fracture risk: a populationbased analysis. J Clin Oncol 2008;26:5227-32.

20. Kristensen B, Ejlertsen B, Mouridsen HT, Andersen KW, Lauritzen JB. Femoral fractures in postmenopausal breast cancer patients treated with adjuvant tamoxifen. Breast Cancer Res Treat 1996;39:321-6.

21. Pawloski PA, Geiger AM, Haque R, Kamineni A, Fouayzi H, Ogarek J, et al. Fracture risk in older, longterm survivors of early-stage breast cancer. J Am Geriatr Soc 2013;61:888-95.

22. Feik SA, Storey E, Ellender G. Stress induced periosteal changes. Br J Exp Pathol 1987;68:803-13.

23. Mente PL, Aronsson DD, Stokes IA, Iatridis JC. Mechanical modulation of growth for the correction of vertebral wedge deformities. J Orthop Res 1999;17: 518-24.

24. Mente PL, Stokes IA, Spence H, Aronsson DD. Progression of vertebral wedging in an asymmetrically loaded rat tail model. Spine (Phila Pa 1976) 1997;22:1292-6.

25. Pazzaglia UE, Andrini L, Di Nucci A. The effects of mechanical forces on bones and joints. Experimental study on the rat tail. J Bone Joint Surg Br 1997;79:102430.

26. Wynarsky G, Schultz A. Effects of age and sex on the external induction of scoliosis in rats. Spine (Phila Pa 1976) 1987;12:974-7.

27. Serel S, Tuzlali ZY, Akkaya Z, Uzun C, Kaya B, Bayar S. Physical effects of unilateral mastectomy on spine deformity. Clin Breast Cancer 2017;17:29-33. 